\title{
Sexual dimorphism of frailty and cognitive impairment: Potential underlying mechanisms (Review)
}

\author{
QINGWEI RUAN ${ }^{1}$, GRAZIA D'ONOFRIO ${ }^{2}$, TAO WU $^{1}$, ANTONIO GRECO $^{2}$, \\ DANIELE SANCARLO ${ }^{2}$ and ZHUOWEI YU ${ }^{1}$
}

\begin{abstract}
${ }^{1}$ Department of Geriatrics, Shanghai Key Laboratory of Clinical Geriatrics, Shanghai Institute of Geriatrics and Gerontology, Huadong Hospital and Research Center of Aging and Medicine, Shanghai Medical College, Fudan University, Shanghai 200040, P.R. China; ${ }^{2}$ Department of Medical Sciences, Geriatric Unit and Laboratory of Gerontology and Geriatrics, The Scientific Institute for Research and Health Care, Home for Relief of the Suffering Hospital, San Giovanni Rotondo, Foggia I-71013, Italy
\end{abstract}

Received February 22, 2016; Accepted January 1, 2017

DOI: $10.3892 / \mathrm{mmr} .2017 .6988$

\begin{abstract}
The aim of the present study was to assess systematically gender differences in susceptibility to frailty and cognitive performance decline, and the underlying mechanisms. A systematic assessment was performed of the identified reviews of cohort, mechanistic and epidemiological studies. The selection criteria of the present study included: i) Sexual dimorphism of frailty, ii) sexual dimorphism of subjective memory decline (impairment) and atrophy of hippocampus during early life, iii) sexual dimorphism of late-onset Alzheimer's disease and iv) sexual dimorphism mechanisms underlying frailty and cognitive impairment. Males exhibit a susceptibility to poor memory performance and a severe atrophy of the hippocampus during early life and females demonstrate a higher prevalence for frailty and late-life dementia. The different alterations within the hypothalamic-pituitary-gonadal/adrenal axis, particularly with regard to gonadal hormones, cortisol and dehydroepiandrosterone/sulfate-bound dehydroepiandrosterone
\end{abstract}

Correspondence to: Dr Zhuowei Yu, Department of Geriatrics, Shanghai Key Laboratory of Clinical Geriatrics, Shanghai Institute of Geriatrics and Gerontology, Huadong Hospital and Research Center of Aging and Medicine, Shanghai Medical College, Fudan University, 221 West Yan An Road, Shanghai 200040, P.R. China

E-mail: hdyuzhuowei@163.com

Abbreviations: ABCA1, ATP-binding cassette transporter 1; AD, Alzheimer's disease; IGF-1, growth hormone insulin-like growth factor-1; DHEA(S), decreased dehydroepiandrosterone/ sulfate-bound dehydroepiandrosterone; GnRH, gonadotropin-releasing hormone; HDL, high-density lipoprotein; HPA, hypothalamic-pituitary-adrenocortical axis; HPG, hypothalamic-pituitary-gonadal; LDL, low-density lipoprotein; LDLR, low-density lipoprotein receptor; MCI, mild cognitive impairment; THBS4, thrombospondins- 4

Key words: frailty, memory performance, atrophy of hippocampus, late-onset Alzheimer's disease, gender difference prior to and following andropause in males and menopause in females, serve important roles in sexual dimorphism of frailty and cognitive impairment. These endocrine changes may accelerate immunosenescence, weaken neuroprotective and neurotrophic effects, and promote muscle catabolism. The present study suggested that these age-associated endocrine alterations interact with gender-specific genetic and epigenetic factors, together with immunosenescence and iron accumulation. Environment factors, including psychological factors, are additional potential causes of the sexual dimorphism of frailty and cognitive impairment.

\section{Contents}

1. Introduction

2. Alterations in gonadal hormones and sexual dimorphism of frailty and cognitive impairment

3. Alterations in the hypothalamic-pituitary-adrenocortical axis (HPA) axis and sexual dimorphism of frailty and cognitive impairment

4. Iron and the sexual dimorphism of frailty and cognitive impairment

5. Conclusions

\section{Introduction}

Epidemiologic studies (1,2-10) have revealed that frailty and cognitive impairment appear to be correlated with the sexual dimorphism in elderly people. In communities of elderly people, the weighted average prevalence rate was $9.9 \%[95 \%$ confidence interval (CI) 9.6-10.2] for physical frailty and 44.2\% (CI 44.2-44.7) for pre-physical frailty (1). Physical frailty rose steadily with age: $65-69$ years, 4\%; 70-74 years, $7 \%$; 75-79 years, 9\%; 80-84 years, $16 \%$; and $>85$ years, $26 \%$. Physical frailty was statistically more prevalent in females (9.6\%, CI 9.2-10.0) than in males (5.2\%; CI 4.9-5.5). Sarcopenia is the most common cause of frailty (11). The average prevalence of low skeletal muscular mass over the 
age of 60 was $5-13 \%$, over $50 \%$ in people over the age of $80(12,13)$ and almost $70 \%$ in nursing home residents (14). Low lean mass was present in $33 \%$ of community-dwelling elderly females and $10 \%$ of males in an urban area of Barcelona (15). However, two epidemiologic studies of community-dwelling elderly people in Asia demonstrated that females had a reduced prevalence of sarcopenia ( $0.8 \mathrm{vs}$. $1.3 \%)(16)$ and low muscle mass (2.5 vs. $5.4 \%)$ compared with males (17). This difference may have been partially caused by varying screening criteria.

Alzheimer's disease (AD), the most common type of dementia, slowly and progressively develops with a preclinical stage over decades $(18,19)$. Age and gender are the potent risk factors in late-onset $\mathrm{AD}$, which affects $\sim 10 \%$ of individuals over age 65 years (20). The prevalence of AD is $\sim 1 \%$ between 65 and 69 years and is $>60 \%$ in individuals aged 80-85 (21). A recent study (22) of 1,246 cognitively healthy individuals (age, 30-95 years) revealed sexual dimorphisms in brain aging between males and females. Males exhibited a susceptibility to poor memory performance and a severe atrophy of the hippocampus during early life (age, 40-60 years). However, there was no greater prevalence of late-onset dementia among males. Previous studies of age-associated medical temporal lobe volume decline (23-25) demonstrated that the differences between genders varied considerably. Previous studies have revealed more significant atrophy of hippocampus in males compared with females in early healthy adulthood $(26,27)$. The speculative causes, which affect the signal intensity of Magnetic Resonance Imaging images, include inflammatory processes and the differing alterations in the iron content of the hippocampus cells between males and females (26). Certain epidemiologic studies (28-31) have suggested that there was no sexual difference in the incidence rates of AD. A previous study reported no gender differences in the incidence of dementia up to a high age (32). After 90 years of age the incidence of $\mathrm{AD}$ is greater in females compared with males. In addition, there are different results for the risk of vascular dementia $(2,3,32)$. However, the majority of studies, particularly one large meta-analysis, confirmed that females were at greater risk of developing $\mathrm{AD}$ and deterioration of cognition (2-10). These data appear to be significant even after adjusting for well-known differences in survival rates and reciprocally for education level.

Multiple transgenic mouse models of AD have demonstrated that females are inherently more susceptible to AD pathogenesis compared with males, with earlier and greater pathology and behavioral impairment [see reviews by $\mathrm{Li}$ and Singh (6) and Vest and Pike (33)]. This raises the question as to the cause of early age gender differences in memory performance and brain atrophy and the subsequent risks for frailty and dementia in later life. The aging of the endocrine system is closely associated with sarcopenia, frailty and cognitive impairment (34-37). During healthy aging, endocrine pathways under hypothalamic-pituitary control show age-associated alterations. There are declines in output from the gonadal axis, the growth hormone insulin-like growth factor-1 (IGF-1) axis and decreased dehydroepiandrosterone/sulfate-bound dehydroepiandrosterone [DHEA(S)] output from the adrenal axis; however, there is an increased output of cortisol $(6,7)$. One potential cause may be endocrinologically different alterations within the hypothalamic-pituitary-gonadal (HPG)/adrenal axis, particularly with regard to gonadal hormones, cortisol and DHEA(S) prior to and following andropause in males and menopause in females. In addition, the complex interactions between endocrine and neurophysiological, immune, genetic and epigenetic factors in aging may serve important roles.

The present study conducted literature searches on the PubMed database (https://www.ncbi.nlm.nih.gov/pubmed) to identify relevant papers published between January 1990 and June 2015. The database was searched with the following key words: Frailty, sarcopenia, prevalence, gender difference, memory performance, subjective memory decline (impairment), late-onset $\mathrm{AD}$, endocrine system, aging, gonadal hormones, androgens, estrogens, immunosenescence, brain aging, genetics, cortisol, DHEA(S), iron overload and hippocampal atrophy. The searches were limited to English language articles. In addition, the pertinent references mentioned in the previously identified papers were analyzed.

\section{Alterations in gonadal hormones and sexual dimorphism of frailty and cognitive impairment}

Decline in sex hormones from the gonadal axis. Sex hormones have been considered as the cause of sexual dimorphisms in various pathophysiological alterations. In humans, aging leads to a decline in estrogen and testosterone, with an increase in luteinizing hormone, follicle-stimulating hormone and sex hormone-binding globulin in humans $(38,39)$. Estrogen is produced primarily by developing follicles in the ovaries, and by the corpus luteum and placenta. The secondary sources of estrogen, including the liver and adrenal glands, produce smaller quantities; however, these are important sources of endogenous estrogen that alter little in postmenopausal females. The most significant difference between males and females $>55$ years is the menopause, which results in a rapid decrease in circulating baseline levels of estrogens and androgens (40-43). On average, $80 \%$ of estrogens is lost in females during the first year of menopause with little alterations following the menopause (40). Serum testosterone concentrations in postmenopausal females are $\sim 15 \%$ of premenopausal levels (44). In addition, brain levels of estrogens and androgens exhibit a similar pattern in postmenopausal females (45). The circulating levels of estrogens and androgens in healthy aging males decrease gradually, beginning in the fourth decade (46). Due to the increase in age-associated sex hormone-binding globulin, the decrease of free testosterone is greater compared with total testosterone $(46,47)$. The circulating bioavailable testosterone concentrations decrease $\sim 20 \%$ in males $>60$ years and $50 \%$ in those $>80$ years, compared with young males $(46,47)$. Almost 5\% of males aged 70-79 years demonstrated andropause (48). Testosterone may be converted to estradiol, an active metabolite of estrone, by the aromatase enzyme, which is located peripherally and throughout the male brain. Although the conversion rate of testosterone to estrogen is low, at $\sim 0.2 \%$, it is the primary source of plasma estradiol in males. In contrast to circulating testosterone, the levels of testosterone in male brains exhibit a strong decline and are at their lowest at $\sim 80$ years old (45). Healthy aged males possess a 10-25-fold greater circulating concentration of androgens 
and a 2-4-fold greater quantity of estrogens compared with females (41-43).

Frailty and decline in gonadal hormones. Of the gonadal hormones of the HPG axis, the age-associated decline in testosterone may serve a primary role in decreased muscle mass and strength (49). Mohr et al (50) identified that total and free testosterone levels were not associated with frailty in males. In the Women's Health and Aging Studies, Coppola et al (51) identified that relative deficiency in a number of anabolic hormones, including IGF-1, DHEA(S) and free testosterone, was an independent predictor of frailty, although deficiency of a single hormone was not significantly associated with frailty. However, other studies $(49,52-54)$ have demonstrated that low testosterone levels are associated with sarcopenia and frailty in elderly males. Furthermore, IGF-1, DHEA(S) and free testosterone were each associated with age-related cognitive and physical events (52). In a cohort study (55) of community-dwelling males $\geq 70$ years $(n=1645)$, individuals in the lowest testosterone quintile had 2.2-fold greater odds of demonstrating physical frailty compared with the highest testosterone quintile. Furthermore, a decline in testosterone, calculated free testosterone or luteinizing hormone was associated with 1.2 to 1.3 -fold increase in the severity of frailty at a 2-year follow-up. The relevance of serum free testosterone and frailty is gender-specific. In one cross-sectional study $(n=2,488)$, a U-shaped association between serum free testosterone and frailty, which appeared to be modulated by body mass index, was reported in elderly females (56). The gender-specific association between testosterone and frailty may involve different underlying biological mechanisms.

Cognitive impairment and decline in gonadal hormones. During critical periods of neural development, sex steroid signaling may contribute to the increased vulnerability of females to AD pathology [see review by Vest and Pike (33)]. The levels of circulating gonadal hormones influence cognitive functions. Healthy people also exhibit aging-associated gender differences in cognition. Older males performed worse in mental rotations tasks compared with younger males and older females (57). During brain developmental maturation in puberty, hippocampal volume negatively correlates with the circulating testosterone levels, which cause gender-specific differences in hippocampal volume (58). Thus, male susceptibility to poor memory performance and severe atrophy of the hippocampus during adulthood may be a normal aging process. Estrogens and progesterone possess numerous brain-protective effects against various aspects of AD pathogenesis [see review by Li and Singh (6)]. Females with AD exhibit reduced circulating (59) and brain levels of estrogens compared with age-matched controls $(45,60)$. The circulating and brain estrogens were of gonadal and extra-gonadal sources, which may explain why ovariectomy in wild-type rodents and certain AD mouse models resulted in increased amyloid (A) $\beta$ accumulation, but not in other AD models $(33,60)$. The cognitive function of aged ovariectomized rhesus monkeys may be significantly improved by estrogen replacement (61). The deficiency of estrogens may cause a decrease in hippocampal volume. The partial or complete loss of an X-chromosome in young females results in disproportionately reduced hippocampal volumes compared with age-matched individuals (62). Exogenous estrogen only demonstrated neuroprotective effects in cognitively intact females prior to menopause and accelerated the progression of neurodegeneration once that neurodegeneration process was present at menopause (63). Therefore, the abrupt decline of gonadal hormones at menopause may be a potential reason for the greater prevalence of late-onset AD in females compared with males. The influences of testosterone levels on cognitive functions are controversial. Certain studies $(45,64-66)$ have identified that decreased circulating and brain levels of testosterone in old age were associated with cognitive decline and increased risk of $\mathrm{AD}$ in males. In male 3xTg-AD mice, depletion of endogenous androgens by orchiectomy significantly accelerates AD-like pathology, including $\mathrm{Ab}$ accumulation and cognitive impairment (67). However, another study (68) demonstrated that greater levels of testosterone failed to improve cognitive function. Therefore, certain studies $(33,69)$ have speculated that an optimal level of testosterone is beneficial to cognition. The gender-specific differences of risks for frailty and late-onset $\mathrm{AD}$ involve the underlying mechanisms described below.

Regulation of immunosenescence by gonadal hormones. Estrogens enhance immunity, particularly humoral immunity, and menopause transition with decreased estradiol promotes female immunosenescence. Androgens and progesterone function as an immunosuppressors (70). In chronic inflammatory diseases where monocytes, macrophages, dendritic cells, T cells, fibroblasts and neutrophils serve a dominant role, estrogens demonstrate anti-inflammatory effects by inhibiting numerous pro-inflammatory pathways involved in innate immunity, adaptive immunity and inflammatory tissue responses (71). However, when B cells are dominant in an inflammatory disease, as in the case of systemic lupus erythematosus, estrogens may stimulate the disease process. In addition, estrogens reduce low-density lipoprotein (LDL) and increase high-density lipoprotein (HDL) cholesterol; HDL is a powerful anti-inflammatory agent. Furthermore, estrogens exhibit antioxidant properties by upregulating the expression of genes that encode antioxidant enzymes, which results in a decrease in mitochondrial free-radical production. Thus, compared with males, females are more susceptible to autoimmune diseases and associated infections, and exhibit greater efficacy from vaccinations (72). Females also demonstrate reduced susceptibility to age-associated disorders, including cardiovascular disease and $\mathrm{AD}$, and numerous infectious diseases when compared with males of the same age (70). Due to the age-associated alterations in the levels of sex hormones and corresponding atherogenic lipid serum concentrations, including increases in LDL and total cholesterol and decreases in HDL in menopausal females, the risk of age-associated disorders increases and is similar to males of equivalent age. The improved response to vaccination and the reduced predisposition to infections in females are eliminated following the menopause, when their inflammatory status is characterized by the increased expression of pro-inflammatory cytokines including tumor necrosis factor (TNF)- $\alpha$, interleukin (IL)-1 $\beta$, IL-6, IL-8, IL-13, interferon- $\gamma$ and monocyte chemoattractant protein 1 (71). Inflammatory and stress responses may activate nuclear factor $(\mathrm{NF})-\kappa \mathrm{B}$ in the hypothalamus and induce a 
signaling pathway that results in a reduction in the neuronal production of gonadotropin-releasing hormone (GnRH) (73). This decline in GnRH may contribute to an age-associated reduction in neurogenesis. Therefore, there is a bi-directional connection between the HPG axis and the immune system, which leads to age-associated disorders. The pro-inflammatory status that results from innate immunity senescence is toxic to neurons and affects the metabolism of the amyloid precursor protein. An imbalance between the production of $\mathrm{A} \beta$ by neuronal cells and astrocytes, and its degradation, may trigger chronic inflammatory processes in microglial cells and astrocytes and initiate a vicious cycle that ultimately results in AD (74).

In addition, chronic low grade systemic inflammation is a primary contributor to sarcopenia, frailty and age-associated diseases (75-77). Inflammatory cytokines, including IL-6 and TNF- $\alpha$, activate catabolism of skeletal muscle and cause an imbalance between new muscle cell formation, hypertrophy and protein loss, resulting in the loss of muscle mass and strength (75). Compared with elderly males, menopausal females are more susceptible to certain age-associated diseases, including atherosclerosis, obesity and diabetes, depression, and osteoporosis $(6,78)$. These comorbidities increase the risk of sarcopenia and frailty $(76,79,80)$. The advantages that mitochondria from young females exhibit, including protection against $\mathrm{A} \beta$ toxicity, reduced generation of reactive oxygen species and reduced release of apoptogenic signals compared with males, are lost in mitochondria from older females (81). Thus, the critical mechanisms include low grade inflammation, oxidative stress and decline of anabolic hormones due to vascular perfusion decrease, hypoxaemia and increased insulin resistance. A population-based cohort study of a total of 2,719 participants with a median follow-up of 4 years (82), identified cardiac disease as an independent risk factor for nonamnestic mild cognitive impairment (MCI) in females, which would progress to vascular and other non-AD dementias. Another population-based cohort study (83) demonstrated that type 2 diabetes was associated with a higher risk of amnestic MCI in males and a strong association with single-domain nonamnestic MCI in females. Baseline depression of elderly community-dwelling individuals promotes the conversion of MCI to dementia (84). Apart from comorbidities, sarcopenia in older females is associated with cognitive impairment (85). Physical frailty may predict future cognitive decline (86). Lean mass loss is associated with brain atrophy and cognitive performance and AD patients exhibit an accelerated lean mass loss (87). The connection between frailty and cognitive impairment suggests they share a common pathogenesis $(34-36,76,88,89)$.

Neuroprotective and neurotrophic effects of gonadal hormones. Androgens and estrogens are neuroprotective in males and females, respectively. Estrogens demonstrate neuroprotective (memory preserving) and neurotrophic (memory enhancing) actions in rodents and rhesus monkeys, through nuclear and extranuclear hippocampal estrogen receptors that function to increase spine density and synapse formation $(90,91)$, improve brain structural and functional plasticity by neurotrophin expression and neurogenesis (92-94), regulate brain metabolism (95), effect connectivity within prefrontal-hippocampal circuitry (96), affect the synaptic distribution of estrogen receptor (97), neuronal excitability (94), brain $A \beta$ levels $(95,98,99)$ and hyperphosphorylated $t$ levels (100), and decrease the toxic effects of amyloid (101). In addition, progesterone demonstrates neuroprotective effects against $\mathrm{AD}$ by modulating $\gamma$ secretase and $\mathrm{A} \beta$ production (102), and increasing A $\beta$ clearance (103). A GnRH agonist that suppresses ovarian function in young adult females causes deficits in verbal memory and task-associated neural activity patterns that may be corrected by the administration of exogenous ovarian hormones (104). The rapid decline of ovarian estrogens and progestogens at menopause has been considered as a reason for increased female susceptibility to AD. Furthermore, animal and human studies have suggested that brain estrogen, rather than circulating estradiol, deficiency is more significantly associated with the risk of AD and induced AD-associated neuropathological changes (60).

The associations between sex steroid hormones and AD risk are gender-specific. Although androgens may be converted to estradiol by aromatase enzyme, there is no association between brain estrogens levels and AD risk in males (33). Age-associated reduced levels of available testosterone have been associated with an increased risk of AD. Males with AD demonstrate decreased circulating and brain levels of testosterone compared with age-matched controls $(6,45)$. An optimal level of testosterone exhibits neuroprotective effects by a high density of androgen receptors in the hippocampus and its associated cortical areas $(105,106)$. Testosterone may promote synaptic plasticity $(107,108)$, protect against apoptosis in hippocampal neurons (109) and attenuate Ab toxicity (110). The age-associated decline in androgen levels appears earlier compared with the neuropathological diagnosis of AD and the decline in androgen levels may be a cause of AD.

Genetics may also be a cause of sexual dimorphism of frailty and cognitive impairment. Polymorphisms of the aromatase gene intron 1 (CYP19A1, rs1062033), which codes for a rate-limiting enzyme in the synthesis of estrogens, result in epistatic interactions with IL10-1082 polymorphisms (rs1800896) that are restricted to females $>75$ years old (adjusted synergy factor $=2.29 ; 95 \% \mathrm{CI}, 1.24-4.21 ; \mathrm{P}=0.008$ ) compared with females $<75$ years old $(1.00 ; 95 \%$ CI, 0.28-3.51; $\mathrm{P}=1.00$ ). Each genotype (CYP19A1 interaction $1 \mathrm{CC}+\mathrm{CG}$ and IL10-1028 AA+ AG) is associated with an increased risk of AD in the presence of the other genotype, which could result from the reduction of IL-10 production and estrogen synthesis (111). These age-associated differences are consistent with the epidemiological evidence that demonstrate a greater susceptibility to $\mathrm{AD}$ of females compared with males only in the very elderly, for example, $>80$ years old (7-10).

The effect of apolipoprotein E\&4 (APOE\&4) on the hippocampus and memory performance appears to be more directly associated with co-occurrences of $\beta$-amyloidosis in later life ( $>70$ years of age) on a background of pre-existing structural and cognitive decline that is associated with aging (112). In cognitively healthy elderly individuals, an increased cerebral amyloid burden, which is highly associated with the APOE\&4 genotype (113), is associated with subtle declines in cognitive performance and an increased risk of future dementia $(114,115)$. In addition, in elderly individuals with MCI, the APOE 4 genotype appears to exhibit a more deleterious effect in females 
compared with males on gross hippocampal pathology and memory performance. The presence of one or more ApoE 44 alleles confers a substantially greater risk of AD in females compared with males (116). Females with ApoEs4 demonstrated greater rates of decline in cognitive function compared with male ApoEc 4 carriers (112). Furthermore, compared with male ApoEc4 carriers, female ApoEe4 carriers with MCI possess a greater risk of cardiovascular mortality (117). In late-onset familial AD, ApoEc4 heterozygous females demonstrated a significant 2-fold increased risk of developing AD compared with ApoEc4 heterozygous males (118). In cognitively healthy, late-middle-aged individuals (49 to 67 years old), individuals with different copies of ApoEc4 allele exhibit similar hippocampal volume; therefore, the gender differences in ApoEc4-associated cognitive impairment are not associated with volume alterations of the hippocampus (119). Estrogen has been revealed to improve synaptic sprouting through an APOE-dependent mechanism (120). Therefore, the combined influence of estrogen loss and the presence of the APOE 4 genotype may, in part, account for the reports of an increased risk of late-onset AD in females (2-10). The LDL receptor (LDLR) is a primary ApoE receptor. The rs688T/T genotype that modulates the splicing efficiency of LDLR exon 12 was associated with increased risk of $\mathrm{AD}$ in males but not in females (121).

The thrombospondin-4 (THBS4) gene encodes a glycoprotein involved in inflammatory responses and synaptogenesis. In humans, THBS4 possesses two haplotypes and interacts with gender in influencing THBS4 expression. AD females with haplotype 1 homozygous demonstrate the lowest expression of THBS4 and reduced gray matter volumes (122). Single-nucleotide polymorphism variants of sortilin receptor 1 exhibit gender-specific effects on late-onset AD. Those homozygous males with rs2070045 risk allele demonstrated improved cognitive performance prior to the age of 75 , while females demonstrated overall detrimental effects on cognitive performance (123). ATP-binding cassette transporter 1 (ABCA1) mediates cellular cholesterol efflux. Female carriers of ABCA1 polymorphism rs2230806 demonstrated a 1.75-fold increased risk of late-onset AD compared with non-carrier females (124). In addition, gonadal hormone-induced DNA methylation and histone modifications at specific gene regulatory regions may increase or decrease this susceptibility to AD (125).

\section{Alterations in the hypothalamic-pituitary-adrenocortical axis (HPA) axis and sexual dimorphism of frailty and cognitive impairment}

Alterations in the HPA axis during aging. A remarkable sexual dimorphism in adrenal hormone regulation, including the HPA and adrenal androgen $\operatorname{DHEA}(\mathrm{S})$ axis, may be an important factor in the sexual dimorphism observed in frailty and cognitive impairment. Cortisol, a lipophilic steroid hormone, is released from the cortex of the adrenal glands into circulation by the HPA axis in response to stress; $90 \%$ of cortisol binds to cortisol binding globulin and $8 \%$ to albumin. The cortisol level and rhythm demonstrate age-associated alterations. The mean cortisol levels increase progressively with age $(126,127)$ and the majority of studies indicate that the typical age-associated decline in cortisol across the course of the day is attenuated $(128,129)$. A meta-analysis of 45 studies (130) reported that pharmacological and psychosocial challenge resulted in a significantly greater cortisol stress response in older compared with younger subjects. $\operatorname{DHEA}(\mathrm{S})$ is the most abundant steroid hormone and the circulating level of DHEA, the majority of which is present in the sulfate-bound form DHEA(S), peaks at 20 years old and declines rapidly and markedly from 25 years old (131). By 80 years old, individuals possess DHEA levels only $10-20 \%$ of those of younger counterparts due to an aging-associated reduction of the zona reticularis within the adrenal cortex $(132,133)$.

Healthy older females have reduced levels of DHEA(S) and greater cortisol levels compared with older males and these disparities persist into advanced age $(38,39)$. The differences in cortisol levels in males and females exhibit a progressive increase with aging. Compared with pre-menopausal females and older males, the HPA responses to psychosocial stress in post-menopausal females are increased. This effect of aging on the cortisol response is approximately three times greater in females compared with males (69). The sexual dimorphism in adrenal hormones may serve important roles in the susceptibility to age-associated alterations involved in cardiovascular disease and brain function (126).

Alterations in the HPA axis influence frailty. Regulating the response to stressors by negative feedback at the level of the hippocampus and associated structures is an important function of glucocorticoid. Cortisol serves an important role in the development of vulnerability to stressors in frail subjects. Greater circulating levels and blunted diurnal variation of cortisol are associated with frail community-dwelling elderly females (134). In elderly residents of long-stay institutions, frailty was positively correlated with salivary cortisol level (135). Sarcopenic individuals demonstrated elevated salivary cortisol levels compared with normal lean, sarcopenic-obese or obese subjects (136). Glucocorticoids inhibit protein synthesis and promote protein degradation, increase myostatin and decrease IGF-1 expression (137). Persistently high levels of cortisol, as in Cushing's syndrome, are associated with increased catabolism, contributing to the loss of muscle mass, muscle atrophy, reduced energy expenditure and sarcopenia $(138,139)$. In addition, DHEA(S) levels have been identified to be significantly decreased in frail compared with robust individuals in a small case-control study (140). Furthermore, frail subjects possess decreased levels of serum IGF-1 and increased levels of IL-6 compared with robust, age-matched individuals (140). However, Puts et al (141) reported that low IGF-1 and high IL-6 levels were not consistently associated with frailty, in another longitudinal study.

Dysfunction of the HPA axis may contribute to aging-associated diseases including neuro-cognitive dysfunction (depression, cognitive deficits and AD), and frailty possibly due to sarcopenia. Inflammaging, the coexistence of inflammation and immunodeficiency referred to as immunosenescence, is one of the pathophysiological mechanisms underlying frailty. The aging-associated activation of the HPA axis by numerous non-specific stressors results in an increase in cortisol levels due to decreased glucocorticoid negative feedback at the level of the paraventricular nucleus of the hypothalamus, hippocampus 
and prefrontal cortex, and the levelling of the diurnal pattern of cortisol release (142). Persistent anti-inflammaging, mainly exerted by cortisol, leads to a marked decline of immunological functions and its coexistence with the increased levels of pro-inflammatory cytokines of inflammaging, ultimately exerts negative effects on metabolism, bone density, strength, exercise tolerance, the vascular system, cognitive function and mood. This in turn results in frailty (143). As an abundant circulating adrenal androgen, $\mathrm{DHEA}(\mathrm{S})$ is positively correlated with successful aging and acts directly as a neurosteroid that may possess cardioprotective, antidiabetic, antiobesity and immunoenhancing properties (128). Low serum levels of DHEA(S) predict all-cause and cardiovascular mortality in elderly males (144). Disabled older females with increased DHEA(S) levels are at greater risk of 5-year cancer mortality, whereas these with decreased $\mathrm{DHEA}(\mathrm{S})$ are at greater risk of 5-year cardiovascular mortality (145). In older males and females, frailty is associated with DHEA and gender does not affect the association between increased DHEA levels and reduced frailty status (146); however, obesity attenuated the association. In another cohort of the oldest subjects, investigators reported (147) that female-specific DHEA(S) decline, not baseline level, is associated with functional performance decline, including gait speed and cognition. Due to a deficient feedback regulation of the HPA axis, serum cortisol suppression is less effective in frail individuals following adrenocorticotropic hormone stimulation and causes an increased cortisol DHEA(S) ratio (148).

Alterations in the HPA axis influence the sexual dimorphism of cognitive impairment. Apart from frailty, the increased cortisol and persistent activation of the biological stress system has additional negative effects on age-associated cognitive decline. Age-associated elevations in endogenous cortisol levels contribute to hippocampal atrophy and cognitive impairments, including a decline in memory performance and executive function in patients with Cushing syndrome, depression and AD $(69,149,150)$. Dysfunction of HPA axis activity and psychosocial factors, include chronic feelings of loneliness, low social status and negative age stereotypes, as stressors increase the risk of progressive cognitive impairments, dementia and depression in older people (69).

Cortisol has gender-specific effects on cognitive impairment. Although cortisol is associated with the decline in hippocampal volume for older males but not older females $(26,27)$, older females and young males appear to be the most susceptible to the effect of cortisol on cognitive and socioemotional domains due to increasing levels of HPA axis activity (151-153). The hippocampus and its associated cortical areas serve important roles in declarative memory, which includes the recall of personal experiences and the acquisition of semantic or factual knowledge (154). The hippocampus has a marked structural plasticity. The atrophy of the hippocampus resulting from atrophy of pyramidal cell dendrites and the loss of synapse, but not from death of neurons, is reversible (80). Increased stress responses in older females compared with older males may be associated with a sharp decline of estrogens in post-menopausal females. Excessive levels of cortisol in post-menopausal females may compromise the structural plasticity of the hippocampus by increasing the atrophy of pyramidal cell dendrites, the loss of synapses and inhibiting neurogenesis, and inhibiting the formation of new synapses (80).

\section{Iron and the sexual dimorphism of frailty and cognitive impairment}

Alterations in iron levels during aging. Circulating iron overload is also considered to be a factor in the sexual dimorphism of brain aging. Increased iron levels are observed in males during adolescence (age, 18-30 years) (155). Of 30- to 70-year-old males, $9.4 \%$ had ample iron stores, whereas $1.4 \%$ had exhausted iron stores and $0.24 \%$ had iron deficiency anaemia. In females, serum ferritin levels remained low from adolescence until the menopause. Of 30- to 50-year-old premenopausal females, $0.49 \%$ had ample iron stores, whereas $18 \%$ had depleted iron reserves and $2.6 \%$ had iron deficiency anaemia (156). The loss of iron in menstrual blood has been postulated to be a uterine function to contribute to a decrease in the risk of cardiovascular disease risk in young females $(157,158)$. During menopausal transition, levels of serum ferritin increase 2 - to 3 -fold $(159,160)$. The corresponding body iron storage from $4.8 \mathrm{mg} / \mathrm{kg}$ bodyweight at the beginning of perimenopause at age 45 years increases to $12 \mathrm{mg} / \mathrm{kg}$ bodyweight following menopause at age 60 years. Serum ferritin increased from baseline to 24-month follow-up during the menopause transition: 37 (CI 20-79) to 67 (CI 36-97) ng/ml ( $\mathrm{P}<0.01)$, but remained lower compared with males: $111 \mathrm{ng} / \mathrm{ml}(\mathrm{CI} 45-220$; $\mathrm{P}<0.01)$ (161). Following menopause, serum ferritin gradually increased and approached levels in males. Of 60- to 70-year-old postmenopausal females, 3.0\% had ample iron stores, 2.3\% had depleted stores and none had iron deficiency anaemia (156). Brain iron levels increase with age and males exhibit greater levels of stored iron in brain compared with females across their lifespan (162).

Iron influences the sexual dimorphism of frailty. Iron deficiency and excess cause deleterious clinical outcomes. Among older adults, anemia prevalence is increased as it is associated with iron deficiency. Anemia or mildly reduced hemoglobin may accelerate the development of frailty and increase the risk of dependence, physical decline, falls and fractures, frailty, cognitive decline and even mortality $(163,164)$. Iron, recognized as a potent pro-oxidant and a catalyst for the formation of reactive oxygen species in biological systems, is essential for oxygen transport, DNA synthesis and energy production (165). Aging-associated iron accumulation may contribute to the decline in muscle function due to increasing oxidative damage. A study of a rat model of sarcopenia (166) demonstrated that the non-heme iron concentration in gastrocnemius muscle increased by 2 -fold and the levels of oxidized RNA were significantly increased between 29 and 37 months of age. Although the role of iron in frailty has yet to be elucidated, the greater levels of stored iron in males and in postmenopausal females is responsible for the pathogenesis of numerous diseases, including ischemic heart disease, cancer, diabetes, infections and neurodegenerative disorders $(159,165,167)$. Gender-specific alterations in the endocrine system and iron level may contribute to the sexual dimorphism of frailty. 
Oxidative and informatory damage serve critical roles in frailty resulting from iron accumulation.

Iron influences the sexual dimorphism of cognitive impairment. Iron deficiency, which affects the differentiation of oligodendrocytes and the continual process of myelin repair or replacement, has adverse consequences on cognition (168). Abnormally high levels of iron in the brain promote oxidative and inflammatory damage to vulnerable brain tissue, which is observed in age-associated neurodegenerative diseases including preclinical AD, MCI, AD and dementia with Lewy bodies $(169,170)$. In healthy older males, declarative memory function is adversely affected by increased hippocampal levels of ferritin iron (168). These results support the hypothesis of an early-age-onset of poor memory function in males. However, iron overload in males occurs during later life in conjunction with a slow decline of male sex hormones, which may provide protection against the harmful effects of the increased iron levels. The increase in iron levels in females occurs at the same time as the rapid decrease in female sex hormones levels, which may be the cause of increased susceptibility to late-onset $\mathrm{AD}$ (40). Elevated brain iron levels may be a mechanism for the susceptibility of AD from ApoEc4 (171). Therefore, the combined effects of iron overload, deficiency of gonadal hormones and the ApoE genotype may exert significant effects on the health of females and increase the risk of late-onset dementia.

Estrogen and iron homeostasis. Serum iron accumulation is conversely associated with the estrogen level in females and ferritin is significantly increased in postmenopausal compared with in premenopausal females $(40,172)$. Estrogen deficiency and a concurrent increased iron retention are risk factors affecting the health of postmenopausal females, including cardiovascular disease (172-174), osteoporosis and late-onset AD (40). Estrogen regulates iron metabolism through hepcidin-ferroportin signaling via an estrogen response element (175-177). Iron homeostasis is closely regulated by the hepcidin-ferroportin axis. Hepcidin is the master regulator of the hepcidin-ferroportin axis and the promoter region of the hepcidin gene has an estrogen response element. In ovariectomized mice, the transcription of hepatic hepcidin was elevated compared with the control (176). An in vitro study (177) demonstrated that the transcription of hepcidin was suppressed by $17 \beta$-estradiol (E2) treatment in human liver $\mathrm{HuH7}$ and HepG2 cells and this downregulation was blocked by E2 antagonist ICI 182780. Ferroportin, the only known iron exporter in the majority of mammalian cells, regulates the level of intracellular iron and maintains iron homeostasis. Estrogen regulates iron metabolism by inhibiting hepatic ferroportin expression via a functional estrogen response element within the ferroportin promoter. Estrogen receptor antagonist tamoxifen attenuates the inhibitory effect of estrogen (175). Thus, estrogen deficiency results in increases in hepcidin and ferroportin and the overload of iron.

\section{Conclusions}

The male prevalence of poor memory performance and severe atrophy of the hippocampus in early life may result from reduced circulating estrogens and greater circulating iron overload compared with females. The increased risk for late-life frailty and dementia in postmenopausal females compared with males may involve brain iron elevation, in combination with multiple hormonal derangement, including a sharp decline of circulating estrogens and androgens, and persistent greater cortisol and reduced DHEA(S) levels. The aging endocrine system, particularly sexual dimorphism alterations within the HPG/adrenal axis, interacts with neurophysiological, psychological, immune, genetic and epigenetic factors, and iron aggregation may contribute to the sexual dimorphism of brain aging; however, their exact roles remain to be elucidated. A systematic assessment of the above interdependent factors may further the understanding of the underlying mechanisms of the sexual dimorphisms of frailty and cognitive impairment, and provide gender-specific interventions, including iron chelators, anti-oxidant, anti-inflammatory and multiple anabolic hormone-replacement therapy for frailty and cognitive impairment.

\section{Acknowledgements}

The present study was supported by the Shanghai Hospital Development Center (grant no. SHDC12014221) and the Shanghai Key Laboratory of Clinical Geriatric Medicine (grant no. 13dz2260700).

\section{References}

1. Collard RM, Boter H, Schoevers RA and Oude Voshaar RC: Prevalence of frailty in community-dwelling older persons: A systematic review. J Am Geriatr Soc 60: 1487-1492, 2012.

2. Fujishima $M$ and Kiyohara Y: Incidence and risk factors of dementia in a defined elderly Japanese population: The Hisayama study. Ann NY Acad Sci 977: 1-8, 2002.

3. Andersen K, Launer LJ, Dewey ME, Letenneur L, Ott A, Copeland JR, Dartigues JF, Kragh-Sorensen P, Baldereschi M, Brayne C, et al: Gender differences in the incidence of AD and vascular dementia: The EURODEM Studies. EURODEM Incidence Research Group. Neurology 53: 1992-1997, 1999.

4. Gao S, Hendrie HC, Hall KS and Hui S: The relationships between age, sex, and the incidence of dementia and Alzheimer disease: A meta-analysis. Arch Gen Psychiatry 55: 809-815, 1998.

5. Read S, Pedersen NL, Gatz M, Berg S, Vuoksimaa E, Malmberg B, Johansson B and McClearn GE: Sex differences after all those years? Heritability of cognitive abilities in old age. J Gerontol B Psychol Sci Soc Sci 61: P137-P143, 2006.

6. Li R and Singh M: Sex differences in cognitive impairment and Alzheimer's disease. Front Neuroendocrinol 35: 385-403, 2014.

7. Letenneur L, Gilleron V, Commenges D, Helmer C, Orgogozo JM and Dartigues JF: Are sex and educational level independent predictors of dementia and Alzheimer's disease? Incidence data from the PAQUID project. J Neurol Neurosurg Psychiatry 66: 177-183, 1999.

8. Fratiglioni L, Viitanen M, Von Strauss E, Tontodonati V, Herlitz A and Winblad B: Very old women at highest risk of dementia and Alzheimer's disease: Incidence data from the kungsholmen project, stockholm. Neurology 48: 132-138, 1997.

9. Ott A, Breteler MM, Van Harskamp F, Stijnen T and Hofman A: Incidence and risk of dementia. The rotterdam study. Am J Epidemiol 147: 574-580, 1998

10. Matthews F and Brayne C; Medical Research Council Cognitive Function and Ageing Study Investigators: The incidence of dementia in England and Wales: Findings from the five identical sites of the MRC CFA study. PLoS Med 2: e193, 2005.

11. Roubenoff R: Sarcopenia: A major modifiable cause of frailty in the elderly. J Nutr Health Aging 4: 140-142, 2000. 
12. Baumgartner RN, Koehler KM, Gallagher D, Romero L, Heymsfield SB, Ross RR, Garry PJ and Lindeman RD: Epidemiology of sarcopenia among the elderly in New Mexico. Am J Epidemiol 147: 755-763, 1998.

13. Morley JE, Anker SD and von Haehling S: Prevalence, incidence, and clinical impact of sarcopenia: Facts, numbers, and epidemiology-update 2014. J Cachexia Sarcopenia Muscle 5 253-259, 2014.

14. Legrand D, Vaes B, Mathei C, Swine C and Degryse JM: The prevalence of sarcopenia in very old individuals according to the European consensus definition: Insights from the BELFRAIL study. Age Ageing 42: 727-734, 2013.

15. Masanes F, Culla A, Navarro-Gonzalez M, Navarro-Lopez MC, Sacanella E, Torres B and Lopez-Soto A: Prevalence of sarcopenia in healthy community-dwelling elderly in an urban area of Barcelona (Spain). J Nutr Health Aging 16: 184-187, 2012.

16. Kim YS, Lee Y, Chung YS, Lee DJ, Joo NS, Hong D, Song Ge Kim HJ, Choi YJ and Kim KM: Prevalence of sarcopenia and sarcopenic obesity in the Korean population based on the fourth Korean national health and nutritional examination surveys. J Gerontol A Biol Sci Med Sci 67: 1107-1113, 2012.

17. Wu IC, Lin CC, Hsiung CA, Wang CY, Wu CH, Chan DC, Li TC, Lin WY, Huang KC, Chen CY, et al: Epidemiology of sarcopenia among community-dwelling older adults in Taiwan: A pooled analysis for a broader adoption of sarcopenia assessments. Geriatr Gerontol Int 14 (Suppl 1): S52-S60, 2014

18. Jack CR Jr, Knopman DS, Jagust WJ, Petersen RC, Weiner MW, Aisen PS, Shaw LM, Vemuri P, Wiste HJ, Weigand SD, et al: Tracking pathophysiological processes in Alzheimer's disease: An updated hypothetical model of dynamic biomarkers. Lancet Neurol 12: 207-216, 2013.

19. Villemagne VL, Burnham S, Bourgeat P, Brown B, Ellis KA Salvado O, Szoeke C, Macaulay SL, Martins R, Maruff P, et al: Amyloid $\beta$ deposition, neurodegeneration, and cognitive decline in sporadic Alzheimer's disease: A prospective cohort study. Lancet Neurol 12: 357-67, 2013.

20. Evans DA, Funkenstein HH, Albert MS, Scherr PA, Cook NR, Chown MJ, Hebert LE, Hennekens $\mathrm{CH}$ and Taylor JO: Prevalence of Alzheimer's disease in a community population of older persons. Higher than previously reported. JAMA 262: 2551-2556, 1989.

21. Hy LX and Keller DM: Prevalence of AD among whites: A summary by levels of severity. Neurology 55: 198-204, 2000.

22. Jack CR Jr, Wiste HJ, Weigand SD, Knopman DS Vemuri P, Mielke MM, Lowe V, Senjem ML, Gunter JL, Machulda MM, et al: Age, sex, and APOE $\varepsilon 4$ effects on memory, brain structure, and $\beta$-amyloid across the adult life span. JAMA Neurol 72: 511-519, 2015.

23. Coffey CE, Lucke JF, Saxton JA, Ratcliff G, Unitas LJ, Billig B and Bryan RN: Sex differences in brain aging: A quantitative magnetic resonance imaging study. Arch Neurol 55: 169-179, 1998

24. Murphy DG, DeCarli C, McIntosh AR, Daly E, Mentis MJ, Pietrini P, Szczepanik J, Schapiro MB, Grady CL, Horwitz B and Rapoport SI: Sex differences in human brain morphometry and metabolism: An in vivo quantitative magnetic resonance imaging and positron emission tomography study on the effect of aging. Arch Gen Psychiatry 53: 585-594, 1996.

25. Raz N, Gunning FM, Head D, Dupuis JH, McQuain J, Briggs SD, Loken WJ, Thornton AE and Acker JD: Selective aging of the human cerebral cortex observed in vivo: Differential vulnerability of the prefrontalgray matter. Cereb Cortex 7: 268-282, 1997.

26. Pruessner JC, Collins DL, Pruessner M and Evans AC: Age and gender predict volume decline in the anterior and posterior hippocampus in early adulthood. J Neurosci 21: 194-200, 2001.

27. Bouix S, Pruessner JC, Louis Collins D and Siddiqi K: Hippocampal shape analysis using medial surfaces. Neuroimage 25 1077-1089, 2005

28. Kokmen E, Beard CM, O'Brien PC and Kurland LT: Epidemiology of dementia in Rochester, Minnesota. Mayo Clin Proc 71: 275-282, 1996.

29. Nitrini R, Caramelli P, Herrera E Jr, Bahia VS, Caixeta LF, Radanovic M, Anghinah R, Charchat-Fichman H, Porto CS, Carthery MT, et al: Incidence of dementia in a community-dwelling Brazilian population. Alzheimer Dis Assoc Disord 18: 241-246, 2004

30. Edland SD, Rocca WA, Petersen RC, Cha RH and Kokmen E: Dementia and Alzheimer disease incidence rates do not vary by sex in Rochester, Minn. Arch Neurol 59: 1589-1593, 2002.
31. Katz MJ, Lipton RB, Hall CB, Zimmerman ME, Sanders AE, Verghese J, Dickson DW and Derby CA: Age-specific and sex-specific prevalence and incidence of mild cognitive impairment, dementia, and Alzheimer dementia in blacks and whites: A report from the einstein aging study. Alzheimer Dis Assoc Disord 26: 335-343, 2012.

32. Ruitenberg A, Ott A, van Swieten JC, Hofman A and Breteler MM: Incidence of dementia: Does gender make a difference? Neurobiol Aging 22: 575-580, 2001.

33. Vest RS and Pike CJ: Gender, sex steroid hormones, and Alzheimer's disease. Horm Behav 63: 301-307, 2013.

34. Ruan Q, Yu Z, Chen M, Bao Z, Li J and He W: Cognitive frailty, a novel target for the prevention of elderly dependency. Ageing Res Rev 20: 1-10, 2015

35. Panza F, Solfrizzi V, Barulli MR, Santamato A, Seripa D, Pilotto A and Logroscino G: Cognitive Frailty: A systematic review of epidemiological and neurobiological evidence of an age-related clinical condition. Rejuvenation Res 18: 389-412, 2015 .

36. Clegg A, Young J, Iliffe S, Rikkert MO and Rockwood K: Frailty in elderly people. Lancet 381: 752-762, 2013.

37. Halil M, Cemal Kizilarslanoglu M, Emin Kuyumcu M, Yesil Y and Cruz Jentoft AJ: Cognitive aspects of frailty: Mechanisms behind the link between frailty and cognitive impairment. J Nutr Health Aging 9: 276-283, 2015.

38. Chahal HS and Drake WM: The endocrine system and ageing. J Pathol 211: 173-180, 2007.

39. Lamberts SW, van den Beld AW and van der Lely AJ: The endocrinology of aging. Science 278: 419-424, 1997.

40. Jian J, Pelle E and Huang X: Iron and menopause: Does increased iron affect the health of postmenopausal women? Antioxid Redox Signal 11: 2939-2943, 2009.

41. Goodman-Gruen D and Barrett-Connor E: Sex differences in the association of endogenous sex hormone levels and glucose tolerance status in older men and women. Diabetes Care 23: 912-918, 2000.

42. Militello A, Vitello G, Lunetta C, Toscano A, Maiorana G, Piccoli T and La Bella V: The serum level of free testosterone is reduced in amyotrophic lateral sclerosis. J Neurol Sci 195: 67-70, 2002

43. Paoletti AM, Congia S, Lello S, Tedde D, Orrù M, Pistis M, Pilloni M, Zedda P, Loddo A and Melis GB: Low androgenization index in elderly women and elderly men with Alzheimer's disease. Neurology 62: 301-303, 2004.

44. Longcope C: Androgen metabolism and the menopause. Semin Reprod Endocrinol 16: 111-115, 1998.

45. Rosario ER, Chang L, Head EH, Stanczyk FZ and Pike CJ: Brain levels of sex steroid hormones in men and women during normal aging and in Alzheimer's disease. Neurobiol Aging 32: 604-613, 2011.

46. Ferrini RL and Barrett-Connor E: Sex hormones and age: A cross-sectional study of testosterone and estradiol and their bioavailable fractions in community-dwelling men. Am J Epidemiol 147: 750-754, 1998

47. Harman SM, Metter EJ, Tobin JD, Pearson J and Blackman MR; Baltimore Longitudinal Study of Aging: Longitudinal effects of aging on serum total and free testosterone levels in healthy men. Baltimore longitudinal study of aging. J Clin Endocrinol Metab 86: 724-731, 2001

48. Samaras N, Samaras D, Lang PO, Forster A, Pichard C, Frangos E and Meyer P: A view of geriatrics through hormones. What is the relation between andropause and well-known geriatric syndromes? Maturitas 74: 213-219, 2013.

49. Morley JE and Malmstrom TK: Frailty, sarcopenia, and hormones. Endocrinol Metab Clin North Am 42: 391-405, 2013.

50. Mohr BA, Bhasin S, Kupelian V, Araujo AB, O'Donnell AB and McKinlay JB: Testosterone, sex hormone-binding globulin, and frailty in older men. J Am Geriatr Soc 55: 548-555, 2007.

51. Cappola AR, Xue QL and Fried LP: Multiple hormonal deficiencies in anabolic hormones are found in frail older women: The women's health and aging studies. J Gerontol A Biol Sci Med Sci 64: 243-248, 2009.

52. Morley JE, Kaiser F, Raum WJ, Perry HM III, Flood JF, Jensen J, Silver AJ and Roberts E: Potentially predictive and manipulable blood serum correlates of aging in the healthy human male: Progressive decreases in bioavailable testosterone, dehydroepiandrosterone sulfate, and the ratio of insulin-like growth factor 1 to growth hormone. Proc Natl Acad Sci USA 94: 7537-7542, 1997. 
53. Cawthon PM, Ensrud KE, Laughlin GA, Cauley JA, Dam TT, Barrett-Conno E, Fink HA, Hoffman AR, Lau E, Lane NE, et al: Sex hormones and frailty in older men: The osteoporotic fractures in men (MrOS) study. J Clin Endocrinol Metab 94: 3806-3815, 2009

54. Auyeung TW, Lee JS, Kwok T, Leung J, Ohlsson C, Vandenput L, Leung PC and Woo J: Testosterone but not estradiol level is positively related to muscle strength and physical performance independent of muscle mass: A cross-sectional study in 1489 older men. Eur J Endocrinol 164: 811-817, 2011

55. Travison TG, Nguyen AH, Naganathan V, Stanaway FF, Blyth FM, Cumming RG, Le Couteur DG, Sambrook PN and Handelsman DJ: Changes in reproductive hormone concentrations predict the prevalence and progression of the frailty syndrome in older men: The concord health and ageing in men project. J Clin Endocrinol Metab 96: 2464-2474, 2011.

56. Carcaillon L, Blanco C, Alonso-Bouzón C, Alfaro-Acha A, Garcia-García FJ and Rodriguez-Mañas L: Sex differences in the association between serum levels of testosterone and frailty in an elderly population: The toledo study for healthy aging. PLoS One 7: e32401, 2012.

57. Pilz KS, Konar Y, Vuong QC, Bennett PJ and Sekuler AB: Age-related changes in matching novel objects across viewpoints. Vision Res 51: 1958-1965, 2011.

58. Neufang S, Specht K, Hausmann M, Güntürkün $O$, Herpertz-Dahlmann B, Fink GR and Konrad K: Sex differences and the impact of steroid hormones on the developing human brain. Cereb Cortex 19: 464-473, 2009.

59. Manly JJ, Merchant CA, Jacobs DM, Small SA, Bell K, Ferin M and Mayeux R: Endogenous estrogen levels and Alzheimer's disease among postmenopausal women. Neurology 54: 833-837, 2000.

60. Yue X, Lu M, Lancaster T, Cao P, Honda S, Staufenbiel M, Harada N, Zhong Z, Shen Y and Li R: Brain estrogen deficiency accelerates Abeta b plaque formation in an Alzheimer's disease animal model. Proc Natl Acad Sci USA 102: 19198-19203, 2005.

61. Rapp PR, Morrison JH and Roberts JA: Cyclic estrogen replacement improves cognitive function in aged ovariectomized rhesus monkeys. J Neurosci 23: 5708-5714, 2003.

62. Kesler SR, Garrett A, Bender B, Yankowitz J, Zeng SM and Reiss AL: Amygdala and hippocampal volumes in turner syndrome: A high-resolution MRI study of X-monosomy. Neuropsychologia 42: 1971-1978, 2004.

63. Craig MC, Maki PM and Murphy DG: The women's health initiative memory study: Findings and implications for treatment. Lancet Neurol 4: 190-194, 2005.

64. Moffat SD, Zonderman AB, Metter EJ, Kawas C, Blackman MR, Harman SM and Resnick SM: Free testosterone and risk for Alzheimer disease in older men. Neurology 62: 188-193, 2004.

65. Hogervorst E, Combrinck M and Smith AD: Testosterone and gonadotropin levels in men with dementia. Neuro Endocrinol Lett 24: 203-208, 2003.

66. Moffat SD, Zonderman AB, Metter EJ, Blackman MR, Harman SM and Resnick SM: Longitudinal assessment of serum free testosterone concentration predicts memory performance and cognitive status in elderly men. J Clin Endocrinol Metab 87: 5001-5007, 2002.

67. Rosario ER, Carroll J and Pike CJ: Testosterone regulation of Alzheimer-like neuropathology in male 3xTg-AD mice involves both estrogen and androgen pathways. Brain Res 1359: 281-290, 2010.

68. Emmelot-Vonk MH, Verhaar HJ, Nakhai Pour HR, Aleman A, Lock TM, Bosch JL, Grobbee DE and van der Schouw YT: Effect of testosterone supplementation on functional mobility cognition, and other parameters in older men: A randomized controlled trial. JAMA 299: 39-52, 2008.

69. Ebner NC, Kamin H, Diaz V, Cohen RA and MacDonald K: Hormones as 'difference makers' in cognitive and socioemotional aging processes. Front Psychol 5: 1595, 2015.

70. Giefing-Kröll C, Berger P, Lepperdinger $G$ and Grubeck-Loebenstein B: How sex and age affect immune responses, susceptibility to infections, and response tovaccination. Aging Cell 14: 309-321, 2015.

71. Candore G, Balistreri CR, Colonna-Romano G, Lio D, Listì F, Vasto $\mathrm{S}$ and Caruso C: Gender-related immune-inflammatory factors, age-related diseases, and longevity. Rejuvenation Res 13: 292-297, 2010.
72. Vrachnis N, Zygouris D, Iliodromiti Z, Daniilidis A, Valsamakis $G$ and Kalantaridou S: Probing the impact of sex steroids and menopause-related sex steroid deprivation on modulation of immune senescence. Maturitas 78: 174-178, 2014.

73. Zhang G, Li J, Purkayastha S, Tang Y, Zhang H, Yin Y, Li B, Liu $\mathrm{G}$ and Cai D: Hypothalamic programming of systemic ageing involving IKK- $\beta, N F-\kappa B$ and GnRH. Nature 497: 211-216, 2013.

74. Blasko I, Stampfer-Kountchev M, Robatscher P, Veerhuis R, Eikelenboom P and Grubeck-Loebenstein B: How chronic inflammation can affect the brain and support the development of Alzheimer's disease in old age: The role of microglia and astrocytes. Aging Cell 3: 169-176, 2004.

75. Schaap LA, Pluijm SM, Deeg DJ and Visser M: Inflammatory markers and loss of muscle mass (sarcopenia) and strength. Am J Med 119: 526.e9-17, 2006

76. Fulop T, Larbi A, Witkowski JM, McElhaney J, Loeb M, Mitnitski A and Pawelec G: Aging, frailty and age-related diseases. Biogerontology 11: 547-563, 2010.

77. Ruan Q, Qian F and Yu Z: Effects of polymorphisms in immunity-related genes on the immune system and successful aging. Curr Opin Immunol 29: 49-55, 2014.

78. Lane JM, Serota AC and Raphael B: Osteoporosis: Differences and similarities in male and female patients. Orthop Clin North Am 37: 601-609, 2006.

79. Kalyani RR, Corriere M and Ferrucci L: Age-related and disease-related muscle loss: The effect of diabetes, obesity, and other diseases. Lancet Diabetes Endocrinol 2: 819-829, 2014.

80. Tagliaferri C, Wittrant Y, Davicco MJ, Walrand S and Coxam V: Muscle and bone, two interconnected tissues. Ageing Res Rev 21: 55-70, 2015.

81. Viña J and Lloret A: Why women have more Alzheimer's disease than men: Gender and mitochondrial toxicity of amyloid-beta peptide. J Alzheimers Dis 20 (Suppl 2): S527-S533, 2010.

82. Roberts RO, Geda YE, Knopman DS, Cha RH, Pankratz VS, Boeve BF, Tangalos EG, Ivnik RJ, Mielke MM and Petersen RC: Cardiac disease associated with increased risk of nonamnestic cognitive impairment: Stronger effect on women. JAMA Neurol 70: 374-382, 2013

83. Roberts RO, Knopman DS, Geda YE, Cha RH, Pankratz VS, Baertlein L, Boeve BF, Tangalos EG, Ivnik RJ, Mielke MM and Petersen RC: Association of diabetes with amnestic and nonamnestic mild cognitive impairment. Alzheimers Dement 10: 18-26, 2014.

84. Richard E, Reitz C, Honig LH, Schupf N, Tang MX, Manly JJ, Mayeux R, Devanand D and Luchsinger JA: Late-life depression, mild cognitive impairment, and dementia. JAMA Neurol 70: 374-382, 2013.

85. Nourhashémi F, Andrieu S, Gillette-Guyonnet S, Reynish E, Albarède $\mathrm{JL}$, Grandjean $\mathrm{H}$ and Vellas $\mathrm{B}$ : Is there a relationship between fat-free soft tissue mass and low cognitive function? Results from a study of 7,105 women. J Am Geriatr Soc 50: 1796-1801, 2002.

86. Auyeung TW, Lee JS, Kwok T and Woo J: Physical frailty predicts future cognitive decline-a four-year prospective study in 2737 cognitively normal older adults. J Nutr Health Aging 15: 690-694, 2011.

87. Burns JM, Johnson DK, Watts A, Swerdlow RH and Brooks WM: Reduced lean mass in early Alzheimer disease and its association with brain atrophy. Arch Neurol 67: 428-433, 2010.

88. de la Monte SM: Contributions of brain insulin resistance and deficiency in amyloid-related neurodegeneration in Alzheimer's disease. Drugs 72: 49-66, 2012.

89. Kalyani RR, Varadhan R, Weiss CO, Fried LP and Cappola AR: Frailty status and altered glucose-insulin dynamics. J Gerontol A Biol Sci Med Sci 67: 1300-1306, 2012.

90. Gould E, Woolley CS, Frankfurt M and McEwen BS: Gonadal steroids regulate dendritic spine density in hippocampal pyramidal cells in adulthood. J Neurosci 10: 1286-1291, 1990.

91. Dumitriu D, Hao J, Hara Y, Kaufmann J, Janssen WG, Lou W, Rapp PR and Morrison JH: Selective changes in thin spine density and morphology in monkey prefrontal cortex correlate with aging-related cognitive impairment. J Neurosci 30: 7507-7515, 2010.

92. Pereira AC, Lambert HK, Grossman YS, Dumitriu D, Waldman R, Jannetty SK, Calakos K, Janssen WG, McEwen BS and Morrison JH: Glutamatergic regulation prevents hippocampal-dependent age-related cognitive decline through dendritic spine clustering. Proc Natl Acad Sci USA 111: 18733-18738, 2014. 
93. Galea LA, Wainwright SR, Roes MM, Duarte-Guterman P, Chow $C$ and Hamson DK: Sex, hormones, and neurogenesis in the hippocampus: Hormonal modulation of neurogenesis and potential functional implications. J Neuroendocrinol 25 : 1039-1061, 2013.

94. Spencer JL, Waters EM, Romeo RD, Wood GE, Milner TA and McEwen BS: Uncovering the mechanisms of estrogen effects on hippocampal function. Front Neuroendocrinol 29: 219-237, 2008.

95. Long J, He P, Shen Y and Li R: New evidence of mitochondria dysfunction in the female Alzheimer's disease brain: Deficiency of estrogen receptor- $\beta$. J Alzheimers Dis 30: 545-558, 2012.

96. Ottowitz WE, Siedlecki KL, Lindquist MA, Dougherty DD Fischman AJ and Hall JE: Evaluation of prefrontal-hippocampal effective connectivity following 24 hours of estrogen infusion: An FDG-PET study. Psychoneuroendocrinology 33: 1419-1425, 2008.

97. Waters EM, Yildirim M, Janssen WG, Lou WY, McEwen BS, Morrison JH and Milner TA: Estrogen and aging affect the synaptic distribution of estrogen receptor $\beta$-immunoreactivity in the CA1 region of female rat hippocampus. Brain Res 1379: 86-97, 2011

98. Petanceska SS, Nagy V, Frail D and Gandy S: Ovariectomy and 17beta-estradiol modulate the levels of Alzheimer's amyloid beta peptides in brain. Neurology 54: 2212-2217, 2000.

99. Anastasio TJ: Exploring the contribution of estrogen to amyloid-beta regulation: A novel multifactorial computational modeling approach. Front Pharmacol 4: 16, 2013.

100.Zhang QG, Wang R, Khan M, Mahesh V and Brann DW: Role of Dickkopf-1, an antagonist of the Wnt/beta-catenin signaling pathway, in estrogen-induced neuroprotection and attenuation of tau phosphorylatio. J Neurosci 28: 8430-8441, 2008.

101.Pike CJ: Estrogen modulates neuronal Bcl-xL expression and beta-amyloidinduced apoptosis: Relevance to Alzheimer's disease. J Neurochem 72: 1552-1563, 1999.

102. Jung JI, Ladd TB, Kukar T, Price AR, Moore BD, Koo EH, Golde TE and Felsenstein KM: Steroids as $\gamma$-secretase modulators. FASEB J 27: 3775-3785, 2013

103. Jayaraman A, Carroll JC, Morgan TE, Lin S, Zhao L, Arimoto JM, Murphy MP, Beckett TL, Finch CE, Brinton RD and Pike CJ: $17 \beta$-estradiol and progesterone regulate expression of $\beta$-amyloid clearance factors in primary neuron cultures and female rat brain. Endocrinology 153: 5467-5479, 2012.

104. Sherwin BB and Tulandi T: 'Add-back' estrogen reverses cognitive deficits induced by a gonadotropin-releasing hormone agonist in women with leiomyomata uteri. J Clin Endocrinol Metab 81: 2545-2549, 1996.

105. Holland J, Bandelow S and Hogervorst E: Testosterone levels and cognition in elderly men: A review. Maturitas 69: 322-337, 2011.

106. Gouras GK, Xu H, Gross RS, Greenfield JP, Hai B, Wang R and Greengard P: Testosterone reduces neuronal secretion of Alzheimer's beta-amyloid peptides. Proc Natl Acad Sci USA 97: 1202-1205, 2000.

107.Lau CF, Ho YS, Hung $\mathrm{CH}$, uwongse S, Poon $\mathrm{CH}$, Chiu K, Yang X, Chu LW and Chang RC: Protective effects of testosterone on presynaptic terminals against oligomeric $\beta$-amyloid peptide in primary culture of hippocampal neurons. Biomed Res Int 2014: 103906, 2014

108. Maggio M, Dall'Aglio E, Lauretani F, Cattabiani C, Ceresini G, Caffarra P, Valenti G, Volpi R, Vignali A, Schiavi G and Ceda GP: The hormonal pathway to cognitive impairment in older men. J Nutr Health Aging 16: 40-54, 2012.

109. Nguyen TV, Jayaraman A, Quaglino A and Pike CJ: Androgens selectively protect against apoptosis in hippocampal neurones. J Neuroendocrinol 22: 1013-1022, 2010.

110. Pike CJ: Testosterone attenuates beta-amyloid toxicity in cultured hippocampal neurons. Brain Res 919: 160-165, 2001

111. Medway C, Combarros O, Cortina-Borja M, Butler HT, Ibrahim-Verbaas CA, de Bruijn RF, Koudstaal PJ, van Duijn CM, Ikram MA, Mateo I, et al: The sex-specific associations of the aromatase gene with Alzheimer's disease and its interaction with IL10 in the epistasis project. Eur J Hum Genet 22: 216-220, 2014.

112. Holland D, Desikan RS, Dale AM and McEvoy LK; Alzheimer's Disease Neuroimaging Initiative: Higher rates of decline for women and apolipoprotein E epsilon4 carriers. AJNR Am J Neuroradiol 34: 2287-2293, 2013.

113. Morris JC, Roe CM, Xiong C, Fagan AM, Goate AM, Holtzman DM and Mintun MA: APOE predicts amyloid-beta but not tau Alzheimer pathology in cognitively normal aging. Ann Neurol 67: 122-131, 2010.
114. Pietrzak RH, Lim YY, Ames D, Harrington K, Restrepo C, Martins RN, Rembach A, Laws SM, Masters CL, Villemagne VL, et al: Trajectories of memory decline in preclinical Alzheimer's disease: Results from the Australian imaging, biomarkers and lifestyle flagship study of ageing. Neurobiol Aging 36: 1231-1238, 2015.

115. Morris JC, Roe CM, Grant EA, Head D, Storandt M, Goate AM, Fagan AM, Holtzman DM and Mintun MA: Pittsburgh compound $\mathrm{B}$ imaging and prediction of progression from cognitive normality to symptomatic Alzheimer disease. Arch Neurol 66: 1469-1475, 2009.

116. Fleisher A, Grundman M, Jack CR Jr, Petersen RC, Taylor C, Kim HT, Schiller DH, Bagwell V, Sencakova D, Weiner MF, et al: Sex, apolipoprotein E epsilon 4 status, and hippocampal volume in mild cognitive impairment. Arch Neurol 62: 953-957, 2005.

117. Beydoun MA, Beydoun HA, Kaufman JS, An Y, Resnick SM, O'Brien R, Ferrucci L and Zonderman AB: Apolipoprotein E $\varepsilon 4$ allele interacts with sex and cognitive status to influence all-cause and cause-specific mortality in US older adults. J Am Geriatr Soc 61: 525-534, 2013.

118. Payami H, Zareparsi S, Montee KR, Sexton GJ, Kaye JA, Bird TD, Yu CE, Wijsman EM, Heston LL, Litt M and Schellenberg GD Gender difference in apolipoprotein E-associated risk for familial Alzheimer disease: A possible clue to the higherincidence of Alzheimer disease in women. Am J Hum Genet 58: 803-811, 1996.

119. Protas HD, Chen K, Langbaum JB, Fleisher AS, Alexander GE, Lee W, Bandy D, de Leon MJ, Mosconi L, Buckley S, et al: Posterior cingulate glucose metabolism, hippocampal glucose metabolism, and hippocampal volume in cognitively normal, late-middle-aged persons at 3 levels of genetic risk for Alzheimer disease. JAMA Neurol 70: 320-325, 2013.

120. Stone DJ, Rozovsky I, Morgan TE, Anderson CP and Finch CE: Increased synaptic sprouting in response to estrogen via an apolipoprotein E-dependent mechanism: Implications for Alzheimer's disease. J Neurosci 18: 3180-3185, 1998.

121.Zou F, Gopalraj RK, Lok J, Zhu H, Ling IF, Simpson JF, Tucker HM, Kelly JF, Younkin SG, Dickson DW, et al: Sex-dependent association of a common low-density lipoprotein receptor polymorphism with RNA splicing efficiency in the brain and Alzheimer's disease. Hum Mol Genet 17: 929-935, 2008.

122. Cagliani R, Guerini FR, Rubio-Acero R, Baglio F, Forni D, Agliardi C, Griffanti L, Fumagalli M, Pozzoli U, Riva S, et al: Long-standing balancing selection in the THBS4 gene: Influence on sex-specific brain expression and gray matter volumes in Alzheimer disease. Hum Mutat 34: 743-753, 2013.

123. Reynolds CA, Zavala C, Gatz M, Vie L, Johansson B, Malmberg B, Ingelsson E, Prince JA and Pedersen NL: Sortilin receptor 1 predicts longitudinal cognitive change. Neurobiol Aging 34: 1710.e11-e18, 2013.

124. Sundar PD, Feingold E, Minster RL, DeKosky ST and Kamboh MI: Gender-specific association of ATP-binding cassette transporter 1 (ABCA1) polymorphisms with the riskof late-onset Alzheimer's disease. Neurobiol Aging 28: 856-862, 2007.

125. Kaminsky Z, Wang SC and Petronis A: Complex disease, gender and epigenetics. Ann Med 38: 530-544, 2006.

126. Laughlin GA and Barrett-Connor E: Sexual dimorphism in the influence of advanced aging on adrenal hormone levels: The rancho bernardo study. J Clin Endocrinol Metab 85: 3561-3568, 2000.

127. Nater UM, Hoppmann CA and Scott SB: Diurnal profiles of salivary cortisol and alpha-amylase change across the adult lifespan: Evidence from repeated daily life assessments. Psychoneuroendocrinology 38: 3167-3171, 2013.

128. Yen SS and Laughlin GA: Aging and the adrenal cortex. Exp Gerontol 33: 897-910, 1998.

129. Heaney JL, Phillips AC and Carroll D: Ageing, depression, anxiety, social support and the diurnal rhythm and awakening response of salivary cortisol. Int J Psychophysiol 78: 201-208, 2010.

130. Burke HM, Davis MC, Otte C and Mohr DC: Depression and cortisol responses to psychological stress: A meta-analysis. Psychoneuroendocrinology 30: 846-856, 2005.

131. Orentreich N, Brind JL, Rizer RL and Vogelman JH: Age changes and sex differences in serum dehydroepiandrosterone sulfateconcentrations throughout adulthood. J Clin Endocrinol Metab 59: 551-555, 1984.

132. Vermeulen A: Dehydroepiandrosterone sulfate and aging. Ann NY Acad Sci 774: 121-127, 1995.

133. Parker CR Jr, Mixon RL, Brissie RM and Grizzle WE: Aging alters zonation in the adrenal cortex of men. J Clin Endocrinol Metab 82: 3898-3901, 1997. 
134. Varadhan R, Walston J, Cappola AR, Carlson MC, Wand GS and Fried LP: Higher levels and blunted diurnal variation of cortisol in frail older women. J Gerontol A Biol Sci Med Sci 63: 190-195, 2008.

135. Holanda CM, Guerra RO, Nóbrega PV, Costa HF, Piuvezam MR and Maciel ÁC: Salivary cortisol and frailty syndrome in elderly residents of long-stay institutions: Across-sectional study. Arch Gerontol Geriatr 54: e146-e151, 2012.

136. Waters DL, Qualls CR, Dorin RI, Veldhuis JD and Baumgartner RN: Altered growth hormone, cortisol, and leptin secretion in healthy elderly persons with sarcopenia and mixed body composition phenotypes. J Gerontol A Biol Sci Med Sci 63: 536-541, 2008.

137. Schakman O, Gilson H and Thissen JP: Mechanisms of glucocorticoid-induced myopathy. J Endocrinol 197: 1-10, 2008.

138. Attaix D, Mosoni L, Dardevet D, Combaret L, Mirand PP and Grizard J: Altered responses in skeletal muscle protein turnover during aging in anabolic and catabolic periods. Int J Biochem Cell Biol 37: 1962-1973, 2005.

139. Gupta A and Gupta Y: Glucocorticoid-induced myopathy: Pathophysiology, diagnosis, and treatment. Indian J Endocrino Metab 17: 913-916, 2013

140.Leng SX, Cappola AR, Andersen RE, Blackman MR, Koenig K, Blair $M$ and Walston JD: Serum levels of insulin-like growth factor-I (IGF-I) and dehydroepiandrosterone sulfate (DHEA-S), and their relationships with serum interleukin-6, in the geriatric syndrome of frailty. Aging Clin Exp Res 16: 153-157, 2004.

141.Puts MT, Visser M, Twisk JW, Deeg DJ and Lips P: Endocrine and inflammatory markers as predictors of frailty. Clin Endocrinol (Oxf) 63: 403-411, 2005.

142. Gupta D and Morley JE: Hypothalamic-pituitary-adrenal (HPA) axis and aging. Compr Physiol 4: 1495-1510, 2014.

143. Giunta S: Exploring the complex relations between inflammation and aging (inflamm-aging): Anti-inflamm-aging remodelling of inflamm-aging, from robustness to frailty. Inflamm Res 57: 558-563, 2008.

144. Ohlsson C, Labrie F, Barrett-Connor E, Karlsson MK, Ljunggren O, Vandenput L, Mellström D and Tivesten A: Low serum levels of dehydroepiandrosterone sulfate predict all-cause and cardiovascular mortality in elderly Swedish men. J Clin Endocrinol Metab 95: 4406-4414, 2010.

145. Cappola AR, Xue QL, Walston JD, Leng SX, Ferrucci L, Guralnik $J$ and Fried LP: DHEAS levels and mortality in disabled older women: The women's health and aging study I. J Gerontol A Biol Sci Med Sci 61: 957-962, 2006.

146. Voznesensky M, Walsh S, Dauser D, Brindisi J and Kenny AM: The association between dehydroepiandosterone and frailty in older men and women. Age Ageing 38: 401-416, 2009.

147. Sanders JL, Cappola AR, Arnold AM, Boudreau RM, Chaves PH, Robbins J, Cushman M and Newman AB: Concurrent change in dehydroepiandrosterone sulfate and functional performance in the oldest old: Results from the cardiovascular health study all stars study. J Gerontol A Biol Sci Med Sci 65: 976-981, 2010.

148. Carvalhaes-Neto N, Huayllas MK, Ramos LR, Cendoroglo MS and Kater CE: Cortisol, DHEAS and aging: Resistance to cortiso suppression in frail institutionalized elderly. J Endocrinol Invest 26: 17-22, 2003

149.Lee BK, Glass TA, McAtee MJ, Wand GS, Bandeen-Roche K, Bolla KI and Schwartz BS: Associations of salivary cortisol with cognitive function in the Baltimore memory study. Arch Gen Psychiatry 64: 810-818, 2007.

150. Huang CW, Lui CC, Chang WN, Lu CH, Wang YL and Chang CC: Elevated basal cortisol level predicts lower hippocampal volume and cognitive decline in Alzheimer's disease. J Clin Neurosci 16: 1283-1286, 2009.

151. Seeman TE, McEwen BS, Singer BH, Albert MS and Rowe JW: Increase in urinary cortisol excretion and memory declines: MacArthur studies of successful aging. J Clin Endocrinol Metab 82: 2458-2465, 1997.

152. Comijs HC, Gerritsen L, Penninx BW, Bremmer MA, Deeg DJ and Geerlings MI: The association between serum cortisol and cognative decline in older persons. Am J Geriatr Psychiatry 18: 42-50, 2010.

153. Wolf OT, Schommer NC, Hellhammer DH, McEwen BS and Kirschbaum C: The relationship between stress induced cortisol levels and memory differs between men and women. Psychoneuroendocrinology 26: 711-720, 2001.

154. Eichenbaum H: Hippocampus: Cognitive processes and neural representations that underlie declarative memory. Neuron 44 109-120, 2004.
155.Zacharski LR, Ornstein DL, Woloshin S and Schwartz LM: Association of age, sex, and racewith body iron stores in adults: Analysis of NHANES III data. Am Heart J 140: 98-104, 2000.

156. Milman N: Serum ferritin in Danes: Studies of iron status from infancy to old age, during blood donation and pregnancy. Int $\mathrm{J}$ Hematol 63: 103-135, 1996.

157. Sullivan JL: Iron and the sex difference in heart disease risk. Lancet 1: 1293-1294, 1981.

158. Sullivan JL: Are menstruating women protected from heart disease because of, or in spite of, estrogen? Relevance to the iron hypothesis. Am Heart J 145: 190-194, 2003.

159.Zacharski LR, Chow BK, Howes PS, Shamayeva G, Baron JA, Dalman RL, Malenka DJ, Ozaki CK and Lavori PW: Reduction of iron stores and cardiovascular outcomes in patients with peripheral arterial disease: A randomized controlled trial. JAMA 297: 603-610, 2007

160. Milman $\mathrm{N}$ and Kirchhoff $\mathrm{M}$ : Iron stores in 1359, 30- to 60 -year-old Danish women: Evaluation by serum ferritin and hemoglobin. Ann Hematol 64: 22-27, 1992.

161. Raman SV, Sharkey-Toppen TP, Tran T, Liu JX, McCarthy B, He X, Smart S, Gulati M, Wexler R, Simonetti OP and Jackson RD: Iron, inflammation and atherosclerosis risk in men vs. perimenopausal women. Atherosclerosis 241: 249-254, 2015.

162. Bartzokis G, Tishler TA, Lu PH, Villablanca P, Altshuler LL, Carter M, Huang D, Edwards N and Mintz J: Brain ferritin iron may influence age- and gender-related risks of neurodegeneration. Neurobiol Aging 28: 414-423, 2007.

163. Artz AS: Anemia and the frail elderly. Semin Hematol 45: 261-266, 2008

164. Duh MS, Latypova A and Greenberg P: Impact and treatment of anemia in the elderly: Clinical, epidemiological and economic perspectives. Expert Rev Pharmacoecon Outcomes Res 6: 577-590, 2006

165. MacKenzie EL, Iwasaki K and Tsuji Y: Intracellular iron transport and storage: From molecular mechanisms to health implications. Antioxid Redox Signal 10: 997-1030, 2008.

166. Xu J, Knutson MD, Carter CS and Leeuwenburgh C: Iron accumulation with age, oxidative stress and functional decline. PLoS One 3: e2865, 2008

167. Sullivan JL: Is stored iron is safe ? J Lab Clin Med 144: 280-284, 2004.

168. Bartzokis G, Lu PH, Tingus K, Peters DG, Amar CP, Tishler TA, Finn JP, Villablanca P, Altshuler LL, Mintz J, et al: Gender and iron genes may modify associations between brain iron and memory in healthy aging. Neuropsychopharmacology 36: 1375-1384, 2011.

169. Smith MA, Zhu X, Tabaton M, Liu G, McKeel DW Jr, Cohen ML, Wang X, Siedlak SL, Dwyer BE, Hayashi T, et al: Increased iron and free radical generation in preclinical Alzheimer disease and mild cognitive impairment. J Alzheimers Dis 19: 363-372, 2010.

170. Kell DB: Iron behaving badly: Inappropriate iron chelation as a major contributor to the aetiology of vascular and other progressive inflammatory and degenerative diseases. BMC Med Genomics 2: 2, 2009

171. Ayton S, Faux NG and Bush AI: Alzheimer's disease neuroimaging initiative: Ferritin levels in the cerebrospinal fluid predict Alzheimer's disease outcomes and are regulated by APOE. Nat Commun 6: 6760, 2015

172. Berge LN, Bønaa KH and Nordøy A: Serum ferritin, sex hormones, and cardiovascular risk factors in healthy women. Arterioscler Thromb 14: 857-861, 1994.

173. Mascitelli L, Goldstein MR and Pezzetta F: Explaining sex difference in coronary heart disease: Is it time to shift from the oestrogen hypothesis to the ironhypothesis? J Cardiovasc Med (Hagerstown) 12: 64-65, 2011.

174. Masse PG, Dosy J, Cole DE, Evroski J, Allard J and D'Astous M: Is serum ferritin an additional cardiovascular risk factor for all postmenopausal women? Ann Nutr Metab 48: 381-389, 2004.

175. Qian Y, Yin C, Chen Y, Zhang S, Jiang L, Wang F, Zhao M and Liu S: Estrogen contributes to regulating iron metabolism through governing ferroportin signaling via an estrogenresponse element. Cell Signal 27: 934-942, 2015 .

176. Hou Y, Zhang S, Wang L, Li J, Qu G, He J, Rong H, Ji H and Liu S: Estrogen regulates iron homeostasis through governing hepatic hepcidin expression via an estrogen response element. Gene 511: 398-403, 2012

177. Yang Q, Jian J, Katz S, Abramson SB and Huang X: $17 \beta$-Estradiol inhibits iron hormone hepcidin through an estrogen responsive element half-site. Endocrinology 153: 3170-3178, 2012. 